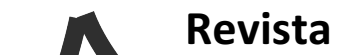 \\ Triângulo
}

\section{A IMPORTÂNCIA DA DIDÁTICA NA PRÁTICA EDUCATIVA E NA FORMAÇÃO DOCENTE}

\author{
THE IMPORTANCE OF DIDACTCISM IN EDUCATIONAL PRACTICE AND \\ TEACHER TRAINING
}

\author{
Cairo Amarildo Batista Martins ${ }^{1}$; Renata Flávia Nobre Canela Dias ${ }^{2}$ \\ e Erika Pereira Silva ${ }^{3}$
}

\begin{abstract}
RESUMO
O ensino e a aprendizagem dos conteúdos exigem do professor não só o domínio específico de conteúdo e disciplinas, mas também o domínio dos elementos que caracterizam uma prática educativa consistente e crítica. Para isto, é necessário conhecer a Didática para a construção do conhecimento coletivo, significativo e contextualizado. Este trabalho tem como intuito apresentar sua importância no cenário de construção e efetivação da prática educativa e na formação docente. Neste viés buscou-se desenvolver o referido artigo por meio de levantamento bibliográfico. Logo, para a sua melhor compreensão, o artigo foi dividido em subtemas, que tentam comprovar que a mesma não pode ser considerada apenas uma ferramenta isolada, mas sim componente indispensável no processo de ensino, que influência no aprendizado e caráter crítico do sujeito. Com este estudo, espera-se trazer de forma clara a importância da Didática e suas possibilidades no espaço educativo, oportunizando novos sentidos às práticas pedagógicas, para a construção dos saberes.
\end{abstract}

Palavras-chave: Didática. Formação. Docente.

\begin{abstract}
The teaching and learning of the contents require the teacher not only the domain-specific content and courses, but also the domain of the elements that characterize a consistent educational practice and criticism. For this, you must know the didactics for the construction of collective knowledge, meaningful and contextualized. This work has the intention to present its importance in the construction setting and execution of educational practice and in teacher education. In this bias we sought to develop that article through literature. So, for your better understanding, the article was divided into subtopics, trying to prove that it can not be considered just an isolated tool, but an indispensable component in the teaching process, which influence learning and critical nature of the subject. This study is expected to bring clearly the importance of didactics and its possibilities in the education space, providing opportunities for new meanings to the pedagogical practices for the construction of knowledge.
\end{abstract}

Keywords: Didacticism. Formation. Teacher.

\footnotetext{
${ }^{1}$ Universidade de Uberaba - UNIUBE. Email: cairo.engenharia@gmail.com

${ }^{2}$ Universidade de Uberaba - UNIUBE. Email: renanobre@hotmail.com

${ }^{3}$ Universidade de Uberaba - UNIUBE. Email: ericaps100@yahoo.com.br
} 


\section{Introdução}

A prática educativa é composta de vários elementos imprescindíveis para a sua completa efetivação. No cenário de construção do conhecimento, temos o professor como mediador de todo processo, sendo o mesmo um dos elementos da ação didática.

Neste trabalho, abordar-se-á a importância da Didática para a efetivação do processo ensino-aprendizagem, ao analisar seus reflexos na prática educativa e implicações na formação docente. É sabido que a Didática é o ramo da ciência pedagógica, que tem como objetivo, ensinar métodos e técnicas que possibilitam e desencadeiam o aprendizado do aluno, com a mediação do professor ou instrutor.

Objetivando a melhor compreensão do mesmo, o presente artigo está dividido em subtemas que apresentarão a conceituação e breves apontamentos históricos da didática, importância da mesma na prática de ensino, na formação docente e as considerações finais.

A metodologia inicial é o levantamento bibliográfico. Logo, com a sua feitura, espera-se levar a compreensão desta relação e importância existente entre os três tópicos centrais desta pesquisa, quais sejam: didática, práticas educativas e formação docente.

\section{DIDÁTICA: BREVES APONTAMENTOS HISTÓRICOS}

“A palavra Didática tem sua origem no verbo grego didasko, que significa ensinar ou instruir" (MORAES, p. 29, 2012), ou melhor, a arte de transmitir conhecimento.

No século XVII, iniciou uma grande euforia dos intelectuais europeus objetivando na reforma dos métodos e formas de ensino de conhecimento humano, de modo a aprofundar e revolucionar a arte de ensinar. Sendo assim, a Didática passa a ser considerada como um método de ensino centrado na razão, buscando observação do ambiente, das semelhanças e diferenças entre os fenômenos. (PIMENTA \& CARVALHO, 2008)

Pimenta (2011, p.17) também afirma que:

Sendo uma área da Pedagogia, a Didática tem no ensino seu objeto de investigação. Considerá-lo uma prática educacional em situações historicamente situadas significa examiná-lo nos contextos sociais nos quais se efetiva [...], estabelecendo os nexos entre eles. As novas 
possibilidades da Didática estão emergindo das investigações sobre o ensino como prática social viva.

Comenius (2001), educador da Europa central também do século XVII, considerado o pai da didática, escreveu o livro intitulado "Didática Magna" onde o lema principal era a prerrogativa de ensinar tudo a todos, assim propôs com sua obra criar um método universal capaz de estabelecer um ensino sem distinção. Com ideais pretenciosos para a sua época, mostrava claramente a preocupação da sociedade acadêmica em disseminar conhecimento para a população, sendo ratificado com um trecho da obra traduzida, que:

Como vimos, a natureza dá as sementes do saber da honestidade e da religião, mas não dá propriamente o saber, a virtude e a religião; estas adquirem-se orando, aprendendo, agindo. Por isso, e não sem razão, alguém definiu o homem, um animal educável, pois não pode tornarse homem a não ser que se eduque. (COMENIUS, p. 30, 2001)

O ser humano por si só é um projeto inacabado. Está em constante desenvolvimento e mudanças de acordo com as necessidades que são postas e encontradas, como afetiva, estética, econômica, social e política.

Isso evidencia o que Comenius (2001) afirmava, que a população necessita de educação, e é obrigação da sociedade garantir o desenvolvimento da raça para viver em harmonia, suprindo suas necessidades de convivência, trabalho, movimentos sociais, organização da sociedade civil e instituições de ensino. Ele também afirmava que a solução para a educação era a criação de um método universal de aprendizagem, onde todos compreenderiam conceitos com concentrações iguais.

Sendo assim, percebe-se que ao entender o homem como um ser que está em constante desenvolvimento e/ou transformação, evidencia-se as constantes necessidades de aprendizagens e condições para que o ensino seja realmente feito e compreendido. Claramente é observado que as pessoas são diferentes, tanto fisicamente quanto intelectualmente, e por isso também aprendem de formas variadas, inclusive se houver algum interesse particular envolvido, que traga maior motivação, inviabilizando qualquer tentativa de universalizar um método de ensino e aprendizagem. 
Mesmo assim, cabe a escola formal, procurar atender as exigências impostas pelo mercado de trabalho, sem com isso esquecer o verdadeiro intuito do ensino, que é valorizar o ser humano como um todo, nos seus aspectos profissionais e sociais, ou seja, dar condições para que o indivíduo cresça e evolua racionalmente.

É de responsabilidade das instituições de educação escolar, como evidencia Vasconcellos (2008, p.98):

... é um sistemático e intencional processo de interação com a realidade, através do relacionamento humano baseado no trabalho com o conhecimento e na organização da coletividade, cuja finalidade é colaborar na formação do educando na sua totalidade -consciência, caráter, cidadania - tendo como mediação fundamental o conhecimento que possibilite a emancipação humana.

Com o desenvolvimento científico na área da educação, a Didática tornou parte de uma disciplina mais ampla: a pedagogia. Esta palavra tem origem grega e significa guiar, conduzir ou transmitir. Do grego é a união das palavras Paidós e Agogós, que significam criança e conduzir. (SIMOR, p.16, 2011) Interessante o estudo desse termo, pois conduzir a criança relacionado a educação, traz o sentido de ciência que estuda e teoriza sobre seu objeto, a educação, investigando enfim o ensino.

Houaiss (2001), define que Didática é a parte da pedagogia que trata de condutas científicas cuja função é tornar a atividade de estudo mais aguçada e eficiente. Atualmente, é considerada uma área que contribui para a educação e para outras diversas áreas das humanas, afim de sempre focar no ensino e aprendizagem do homem.

Existe grande foco no parâmetro ensinar, mas o que realmente significa isso? Obviamente parece uma pergunta fácil de responder, pois claramente afirmara-se que todos nós, somos ensinados constantemente na vida, e desde o momento do nascimento, somos bombardeados de conceitos e formas de agir.

Ensinar, segundo Houaiss (2001), significa repassar e instruir alguém sobre como realizar ou fazer alguma ação e atividade, também no sentido de doutrinar e lecionar, e é nesta última afirmação que fica evidente a definição mais comum, a qual é identificado o professor. 
No entanto, ao pesquisar a origem epistemológica da palavra ensinar, encontramos do latim insigno, cujo sentido é pôr uma marca, distinguir e assinalar.

Foi dito que o objeto de estudo da Didática é o ensino, e este traz consigo atividades de estudo, que podem se dar ou não dentro da sala de aula, pois podem fazer parte de situações que são vividas sem a necessidade de interação com outras pessoas. A pessoa pode, por exemplo, expor um ideal e demonstrar sua posição e defesa do assunto, com base em experiência acumulada ao longo da vida. Então a medida que as pessoas se tornam maduras e sensatas, a visão em relação aos acontecimentos presenciados muda, e isso acontece também com a atividade de estudo, pois é individual.

Mas o que vai caracterizar a atividade se ensino é seu propósito, seu objetivo. Pimenta e Carvalho (apud CORDEIRO, 2007, p. 21) esclarece exemplificando:

Quando narramos um acontecimento numa roda de amigos ou quando a mãe relata aos filhos o seu dia de trabalho na hora do jantar, não há intenção do falante de produzir uma aprendizagem nos seus ouvintes. Já no ensino, todas as atividades são concebidas e planejadas em função desse objetivo. Portanto, a compreensão do conceito de ensino só pode ser feita em referência ao conceito de aprendizagem. (Grifo do autor)

Em outras palavras, é o objetivo dizer a verdadeira intenção do ensino, produzir aprendizagem. Ao que caberia, especificamente nas palavras de Libâneo (2015, p.642), que:

Se a atividade de ensino-aprendizagem (instrução) é a que promove e amplia o desenvolvimento das capacidades intelectuais dos alunos, trata-se de buscar tais capacidades nos procedimentos lógicos e investigativos que deram origem ao conhecimento científico do qual deriva a matéria ensinada. [...] A culminância da aprendizagem é a consolidação do método de pensar por conceitos teóricos das ciências, o que é possibilitado aos alunos por um ensino que leve ao processo de interiorização desses conceitos como meios da sua atividade interna para lidar com a realidade. 
Vale dizer também que o trabalho docente faz parte do ensino, porém para que esse tenha um bom desempenho, também é necessário que além de atividades escritas interessantes, seja utilizada uma boa didática, para despertar o interesse dos alunos. Assim, o professor consegue manter a atenção e a disciplina em sala de aula, propiciando um espaço mais rico e produtivo capaz de promover com mais êxito o crescimento intelectual dos alunos.

\section{DIDÁTICA NA FORMAÇÃO DOCENTE}

Até aqui foi possível observar que a Didática está dentro de um contexto mais amplo, que é a Educação, pois existem dois elementos fundamentais para que se efetive o processo ensino-aprendizagem, sendo eles estudantes e professores. Juntamente com estes, também temos os conteúdos que são ministrados, as estratégias/métodos de ensino, e os mecanismos de avaliação.

Abordou-se ainda que o ser humano tem intenções, interesses e carrega uma vivência cultural distinta. Os alunos, neste mesmo contexto, possuem habilidades e diferentes desafios no decorrer do processo de ensino e aprendizagem. Importante salientar que com a inserção das tecnologias da informação e comunicação (TICs), na educação, as práticas educativas tiveram de ser revistas, para atender ao novo perfil discente, oportunizando novos conhecimentos e competências. (FARIA, p.20, 2009)

$\mathrm{O}$ docente vive sujeito as influências do meio, para atender as expectativas e exigências do novo perfil profissional, devendo este atentar para sua qualificação. Mesmo assim, existem outros desafios que envolvem esse profissional, devido a tamanha complexidade de suas atribuições. Ele tem o papel fundamental de interagir com a realidade através do conhecimento, tendo como objetivo maior formar alunos com consciência crítica, que saibam utilizar o que aprenderam e que se tornem cidadãos conscientes.

Para que isso aconteça, o docente deve ter a capacidade de fazer a mediação do conhecimento histórico elaborado e relevante para formação do corpo discente.

Como fazer essa mediação com salas de aulas cada vez mais lotadas, sabendo da heterogeneidade dos "clientes"? A intenção e intervenção do professor nunca deverá estar abaixo da expectativa dos estudantes, pois assim ficariam desmotivados e sem interesse de acompanhar o ensino proposto. Mesmo assim, deve-se tomar cuidado com o nível de intervenção, pois é necessário que os educandos criem mais, pois certamente não perceberiam 
desafios propostos e não assimilariam bem o conhecimento se tudo fosse passado de forma definida e sem planejamento.

É nesse momento, que valorizamos outras áreas da ciência de forma que sua utilização possa contribuir para a didática no processo educativo. Teorias de ensinoaprendizagem podem contribuir no que se refere a prática de pensar a melhor forma de mediar o conhecimento ao alunado, como por exemplo Lev Vigotski com sua teoria históricocultural.

Lev Semionovitch Vigotski, foi um grande pensador russo que estudou ensino desenvolvimental e psicologia aplicada a educação. Ele afirmava que, "um dos problemas centrais da psicologia geral, evolutiva e pedagógica era descobrir as conexões entre o desenvolvimento da psique da criança e seu ensino de educação" (PRESTES, TUNES \& NASCIMENTO, p. 58, 2013). Ele também abordava em seus estudos a aquisição de conceitos, mostrando que a formação é uma ação do sujeito sobre o meio que é socialmente mediada por outra pessoa e com auxílio de instrumentos e signos, ou seja, traz à tona o caráter social da aprendizagem e métodos de ensino. (PIMENTA \& CARVALHO, 2008)

Esses pensamentos servem e muito para compreensão do aprendiz e também mostram referências para que os mentores se concentrem em estratégias de ensino e em como envolver o sujeito para participação constante da atividade de estudo.

Logo entende-se que o papel fundamental de aplicar e proceder com a didática é do professor. E para isso acontecer de forma satisfatória, ele deve estar inteirado com o conteúdo e disciplinas, e também, disposto a trabalhar e se adaptar as novas gerações que o procedem. Essas novas gerações podem ter exigências diferentes da época do docente, e isso pode atrapalhar no desenvolvimento de seu trabalho. Sempre existirá dogmas a serem, não desconsiderados, mas sim reformados e evoluídos.

O conhecimento é a ferramenta de trabalho do professor, e também, é a estrada que fornecerá experiência e definirá metas para o crescimento dos alunos na escola.

A escola tem a função de mostrar aos estudantes a forma de lidar com o conhecimento e não de defrontar com o que os estes trazem com seus ensinamentos. A aprendizagem vem a partir do momento que o professor consegue ampliar sua visão de modo que reflitam suas atitudes e práticas relacionadas ao conhecimento e sua vida.

Mas não basta o lecionando ter contato com informação para que garanta conhecimento, senão a maior parte da população que tem acesso a rede de internet seriam doutores na área social com o atributo das redes sociais. 
É na escola que se aprende a pensar, agir e também se aprende a aprender. E nesta dinâmica que é importante, ela é movida pelas pessoas que estão ali envolvidas, reconhecendo, estranhando e estabelecendo diferenças entre as pessoas que conhecem e todos os objetos a serem conhecidos. Assim com as palavras de Libâneo (2015, p.642), pode-se determinar:

A culminância da aprendizagem é a consolidação do método de pensar por conceitos teóricos das ciências, o que é possibilitado aos alunos por um ensino que leve ao processo de interiorização desses conceitos como meios da sua atividade interna para lidar com a realidade.

Não basta só o contato com informação para que se adquira conhecimento, é necessária a contextualização, e que tenha sentido para as pessoas envolvidas, pois sem essa interação epistemológica perde-se o sentido de estudo, conforme Libâneo (2015, p. 643) afirma:

[...] para aprender um conteúdo científico, importa mais o domínio do processo de sua origem e desenvolvimento na trajetória de sua constituição como objeto de conhecimento, do que o domínio apenas de seu conteúdo formal, isto é, do seu resultado. Nos processos de ensino-aprendizagem os estudantes, ao incorporarem o conhecimento e as habilidades relacionadas com a constituição desse conhecimento incorporam, também, as capacidades construídas historicamente para desenvolver a consciência e o pensamento teóricos.

Desta forma, o sujeito necessita de ter contato com a informação organizada, e contextualizada com sentido para sua vida. É necessário também que haja uma relação entre o aluno e professor, donde se faz necessário o reconhecimento recíproco das partes. O primeiro deve estar ciente da necessidade de seu interesse, capacidade de aprender e respeitar o seu mentor. O segundo deve reconhecer que tem muito a ensinar, que pode ensinar, mas que devidamente seja relevante para aquele grupo ou sujeito. 
E tudo isso, se passa na sala de aula, que se torna um lugar de construção de conhecimentos e interação de crianças e adultos, sem distinção, considerados iguais e com mesmo potencial.

Existem numeroso projetos pedagógicos, mas têm-se limitado em impor ao discente a repetição e armazenamento forçado de informações, como se fossem comparados com banco de dados de computadores. (BERTAN, ROCHA \& BECHARA, p.129, 2001)

O ser humano não é uma máquina, e a aprendizagem e a memória são interdependentes. E isso ocorre porque os significados da matéria e/ou objeto a ser compreendido sempre estão envolvidos e dependentes do saber retido na memória, ou seja, daquilo que a pessoa já sabe e tem a capacidade de recordar e processar esses dados. (PINTO, p.17, 2001)

O conhecimento que a pessoa carrega influencia a aprendizagem de novos conceitos e informações, como também, voltando o que foi dito, a forma com que o material será organizado e contextualizado para o ensino. Pois é muito mais simples recordar de um acontecimento feliz de nossa infância que aconteceu a vários anos, por exemplo, uma brincadeira com amigos que era prazerosa e estimulante, do que a aula de línguas da semana passada. Isso se dá pela forma que sucedeu e pelo prazer sentido.

A didática vem dar apoio ao focar no prazer educativo, ou melhor dizendo, a forma de envolver o discente pelo sentimento e importância do aprender, desde o momento em que enfrenta o seu assento dentro da sala de aula, até quando retorna pra casa com vontade e busca por aprender mais.

Conforme as palavras de Bertan, Rocha e Bechara (2001, p.129):

A sala de aula não pode ser o espaço apenas de instruir, isto é, transmitir conhecimento, formar o erudito, mas sim ensinar, marcar profundamente com sinais e chegar a um verdadeiro educar. Para o aluno ser educado, é necessário que realize as qualidades que perfazem seu próprio $\mathrm{Eu}$, que realize valores dentro de si. Educar é despertar no educando aqueles elementos positivos que nele se acham adormecidos, como verdade, justiça, amor, solidariedade e liberdade. 
O verdadeiro educador é aquele que através de qualquer que seja a metodologia e/ou método utilizado elucida seu educando o que ele precisa saber para se tornar individualmente um cidadão de caráter. Portanto, não é só tentar impor e impregnar as pessoas de informações e preceitos, mas sim, contribuir para o crescimento pessoal do educando, com o objetivo de conseguir através do ensino a evolução do homem.

\section{CONSIDERAÇÕES FINAIS}

As explanações aqui apresentadas nos levaram a compreender que a Didática, em qualquer área do conhecimento, traz sua verdadeira importância e possui várias características que devem ser consideradas nas práticas dos professores e alunos.

Fica evidente que a prática educativa e a formação docente estão interligadas para a completa efetivação da aprendizagem. Temos que considerar o rumo das práticas pedagógicas afim de determinar a formação de sujeitos cada vez mais independentes e críticos em seu meio. Pessoas capazes de decidirem o melhor pra si e para sua comunidade, compreensivas em com caráter, tanto politicamente quanto socialmente.

A Didática não pode ser considerada apenas uma ferramenta isolada, mas sim um agente que possui uma dimensão técnica muito abrangente, e que utiliza estratégias e métodos variados possibilitando uma compreensão prática educativa na sociedade. Proporciona que o sujeito em contato com o conhecimento decorra de concepções de sociedade, natureza da atividade prática humana e também do processo de conhecimento, trazendo a tona a compreensão da prática educativa dentro de seu "habitat".

\section{REFERÊNCIAS}

BERTAN, Levino; ROCHA, Márcia Santos da; BECHARA, Zuleika Toledo Bechara. Sala de aula: espaço de libertação ou domesticação? Unopar Cient., Ciênc. Hum. Educ., Londrina, v. 1, n. 1, p. 123-131, jun. 2000.

COMENIUS, Iohannis Amos. Didactica Magna. Tradução de Joaquim Ferreira Gomes. Calouste Gulbekian - eBooksBrasil, 2001. 
FARIA, Elísio Vieira de. A tecnologia da informação e da comunicação como ferramenta para a construção e democratização do conhecimento. Scientia FAER, Olímpia - SP, V. 1, Ano 1, $2^{\circ}$ Semestre - 2009

HOUAISS, Antônio; VILLAR, Mauro de Salles. Minidicionário Houaiss da língua portuguesa. Rio de Janeiro: Objetiva, 2001.

LIBANEO, José Carlos. Formação de Professores e Didática para Desenvolvimento Humano. Educ. Real., Porto Alegre, v. 40, n. 2, p. 629-650, jun. 2015.

MORAES, Elaine Emiliano de. Desafios da didática nas licenciaturas: um estudo com professores formados entre cinco e dez anos.2012. 115 p. Dissertação (Mestrado em Educação) - Faculdade de Educação, Universidade de São Paulo.

PIMENTA, Sônia de Almeida; CARVALHO, Ana Beatriz Gomes. Didática e o ensino de geografia. Campina Grande: EDUEP, 2008. 244p.

PIMENTA, Selma Garrido et al. (Org.). Pedagogia Universitária: caminhos para formação de professores. São Paulo: Cortez Editora, 2011.

PINTO, A. C. Memória, cognição e educação: Implicações mútuas. In: Detry, B.; Simas, F. Educação, cognição e desenvolvimento: Textos de psicologia educacional para a formação de professores. Portugal, Faculdade de Psicologia, Universidade do Porto, Lisboa: Edinova, 2001, p. 17-54

PRESTES, Zóia; TUNES, Elizabeth; NASCIMENTO, Ruben. Lev Semionovitch Vigotski: um estudo da vida e da obra da Psicologia Histórico-Cultural. In: LONGAREZI, Andréa Maturano; PUENTES, Roberto Valdés (organizadores). Ensino Desenvolvimental: vida, pensamento e obra dos principais representantes russos. v.1. Uberlândia: EDUFU, 2013, p.4565 
SIMOR, Fábio Reis Clete. A importância do pedagogo fora das salas de aula: Projeto AlfaSol e a nova visão do Pedagogo. 2011. 42 p. Monografia (Licenciatura em Pedagogia) Faculdade de Formação de Professores, Universidade do Estado do Rio de Janeiro, São Gonçalo.

VASCONCELLOS, C. S. Para onde vai o professor: resgate do professor como sujeito de transformação. 18. ed. São Paulo: Libertad, 2008.

RECEBIDO EM: 10/03/2016

APROVADO PARA PUBLICAÇÃO EM: 29/06/2016 